\title{
EFFECTS OF AWARENESS RAISING ACTIVITIES ON REDUCTION OF PREJUDICE AGAINST REFUGEES
}

\author{
Violeta PETROSKA BESHKA, PhD \\ University Ss. Cyril and Methodius, Skopje \\ Faculty of Philosophy - Institute of Psychology \\ Email: vpbeska@yahoo.com
}

\section{Abstract:}

The study was built upon the assumption that people's inclination to fear from and discriminate against refugees stems from the prejudices imposed by the society that are easily nurtured when people lack adequate knowledge about refugees, either because they are not informed about the real situation or because they are misinformed about it. It presents results of an empirical research that is based on pretest-posttest evaluation design conducted as part of a Project supported by the UNHCR office in Skopje and conducted by the Center for Human Rights and Conflict Resolution during 2016-2017. The Project intended to raise young people's awareness about causes of the recent refugee flee and its consequences on refugees through participation of 124 young people (unemployed youth, university students and high-school student) in twoday workshops. Each workshop involved participants in interactive activities that dealt with the issues of forced migration, cultural diversity, stereotypes, prejudices and discrimination, and human rights in general, and in relation to refugees in particular. A questionnaire containing two sets of measures of the participants' level of prejudice towards refugees were first administered before the workshop started (pretest condition) and repeated after the workshop ended (posttest condition). Both sets of measures contained items on Likert scale (range 1-5): one set of 12 items measured negative attitude towards refugees while the other set of 6 items measured social distance. The statistical analysis ( $t$-test) indicated significant differences between means obtained in the two conditions (pretest/posttest) for each of the two sets of measures as well as for each individual item in both sets. This finding, together with the fact that all workshop participants engaged willingly in social/humanitarian actions related to refugees, allowed for the conclusion that working with young people on raising their awareness about refugees' needs and rights is a powerful tool for combating prejudices against refugees.

Keywords: refugees, prejudice, awareness raising, 


\section{Introduction}

According to the office of the UN High Commissioner for Refugees, among 65.6 million forcibly displaced people, 22.5 million are refugees - people that have been forced to flee their country because of persecution (for reasons of race, religion, nationality, political opinion or membership in a particular social group), war, or violence (UNHCR, 2018). Many of these people appear as migrants in other countries and face negative consequences of the prejudices towards them developed by the people in many host countries. Research has demonstrated that the negative public attitudes towards migrants are group-specific and depend on migrants' cultural similarity, educational background, level of work skills, age, gender and race/ethnicity, economic contribution and religion (Crawley, 2005; Verkuyten, Mepham \& Kros, 2017). Research participants who express negative attitudes towards refugees are mostly concerned about maintaining current welfare conditions and community cohesiveness and maximizing economic and health resources for in-group members (Schweitzer, Perkoulidis, Krome \& Ludlow, 2005). Despite the evidence that contradicts the widely spread belief that the incoming refugees are the cause of intensified violence in the host countries (Karasapan, 2017) in eight of the ten European countries, half or more of the surveyed citizens believe that the refugees increase the likelihood of terrorism in their country (Wike, Stokes $\&$ Simmons, 2016). The results of the same survey (Wike et al., 2016) indicate that at least half of the citizens of five European countries included claim that refugees will take away jobs and social benefits, while in all ten countries, "people who have a more negative view of Muslims are also much more concerned about the threat of refugees". According to Bullard (2015) research conducted in Slovenia (Lobnikar, Pagon, Mesko \& Umek, 2002), the United Kingdom (Lynn and Lea 2003), Australia (McKay, Thomas, and Kneebone 2011; Pedersen, Watt, and Hansen 2006), and across multiple nations (Mayda 2006) has demonstrated that people with many false beliefs about refugees (beliefs that refugees are dangerous terrorists or economic exploiters) generally hold negative attitudes toward refugees.

The latest results of the Gallup world poll (Esipova, Fleming \& Ray, 2017) place Macedonia as the least accepting country for migrants (with acceptance index of 1.47 out of a possible 9.0). It might be closely connected to the research evidence revealing that negative public attitudes towards migrants and refugees are influenced by the context in which attitudes are formed, including dominant political and media discourses (Crawley, 2005), since category labels associated with forced migrants and refugees have been found to make a significant difference to people's subsequent evaluations of the social category in question. Research has provided evidence that respondents report more prejudicial attitudes, greater perceived threats to economic interest, social status or welfare of the in-group, and greater intergroup anxiety when responding to questions about unauthorized compared with authorized migrants. (Murray \& Marx, 2013). Research participants tend to be more favorably disposed towards those recognized as refugees than they are towards asylum-seekers and/or other migrants (Augoustinos \& Quinn, 2003; Hatton, 2016; Dempster \& Hargrave, 2017) Research has also indicated that significantly higher levels of anger, fear, threat, and prejudice is associated with asylum seekers compared to 
resettled refugees (Hartley, \& Pedersen, 2015). In general, a profile of involuntary migrants (e.g. "real refugee") is typically defined as deserving of sympathy and support, whereas the one that is assigned to voluntary migrants (e.g. "bogus refugees") is presented as a threat to the country's hospitality and, as such, an understandable target of feelings of anger and resentment (Verkuyten et al., 2017).

Research has provided evidence that negative public attitudes towards migrants and refugees are influenced by the knowledge of asylum and migration issues (Crawley, 2005). Polls reveal that the public's understanding of refugees is shaped by the negative media debate which spreads misinformation and presents very limited positive information about refugees (Griffith \& Chan-Kam, 2002). Based on extensive overview of the existing literature, Dempster \& Hargrave (2017) emphasize that it is sometimes assumed that negative attitudes towards refugees and migrants are based only on inadequate information about migration flows and their consequences and that people need only to learn the facts in order to be discouraged from cherishing antiimmigration beliefs. In fact, the authors question the effectiveness of such 'myth-busting' strategies, arguing that public attitudes rely on real world concerns, in particular those connected to the economy, culture and security, and are based on complex emotions and values. While it is important to ensure that public opinion is not being shaped by misinformation or exaggeration (Griffith \& Chan-Kam, 2002), engaging effectively with public attitudes towards refugees and migrants requires understanding the real world concerns, emotions and values around which attitudes are formed (Dempster \& Hargrave, 2017). The Tent Tracker - a multi-country survey assessing public opinion in relation to the refugee crisis - has revealed that people who had been exposed to information about refugees' sufferings (through photos/videos or news reports) and encouraged to imagine being in their situation became more sympathetic towards refugees (TENT, 2017). It is consistent with the findings that refugees, compared to other migrants, are considered more deserving of empathy that is based on identification with their unfortunate situation and perception that their neediness is beyond their control (Verkuyten et al., 2017).

Current study was built upon the assumption that people's inclination to fear from and discriminate against refugees stems from the prejudices imposed by the society that are easily nurtured when people lack adequate knowledge about refugees, either because they are not informed about the real situation or because they are misinformed about it. Therefore, it is expected that raising awareness about refugees' needs and rights will affect people's values and emotions and eventually lead to reduction of their prejudices towards refugees. 


\section{Security}

\section{Method}

\section{Awareness raising activities ${ }^{11 *}$}

The project Refugee now - always human was conducted in 2016 (from October to December) and 2017 (from June to December) with an overall goal to raise young people's awareness about causes of the recent refugee flee and its consequences on refugees. Project participants, divided in small groups, went through two kinds of awareness raising activities: (1) workshops and (2) follow up activities. The two-day awareness raising workshops involved participants in interactive activities that dealt with the issues of forced migration, cultural diversity, stereotypes, prejudices and discrimination, and human rights in general, and in relation to refugees in particular. Within a period of 3 to 12 weeks after the workshop, participants engaged in different kinds of follow-up public awareness raising activities. High-school students involved in planning and implementation of various advocacy actions in their school and wider community, all in favor of refugees (e.g. humanitarian actions for raising donations in clothes, school supplies and money, exhibitions with drawings done by refugee children and children form a local kindergarten, graffiti drawing, public screening of documentaries about refugees, distribution of awareness raising materials, like informative posters, cookies with messages about refugees, badges and bookmarks, all developed by students-participants, etc.). University students were engaged either in producing illustrated books about the refugees' lives, struggles and hopes, inspired by true stories, or in preparation and delivering of an awareness raising presentation to their colleagues and developing other awareness raising products intended for primary and secondary school students (flash cards, quiz wheel and board game, all related to refugees). Unemployed youth were assigned to participate in the public space installations featuring information on the current refugee crisis through publicly displayed (on squares and/or other frequent pedestrian zones in several towns) image boards and pavement stickers. Their role was to interact with the visitors, provide them with information about refugees, distribute brochures and administer surveys to those that were interested in sharing their thoughts and feelings incited by the installation content.

The design of the awareness raising activities was based on the notion that prejudices are negative attitudes (Allport, 1954) and therefore, it tackled all three components of attitudes: cognitive, affective and behavioral (Breckler, 1984). The awareness raising workshops faced participants with accurate information on causes and consequences of the refugee crises in order to combat stereotypes and misinformation that foster the cognitive component of the prejudices towards refugees. During the workshop, participants saw video material and engaged in discussion about the sufferings and violations of human rights that refugees are exposed to in order to evoke sympathy and induce empathy in an attempt to influence the affective component of

\footnotetext{
11* The data used in this study was collected for the purpose of evaluating the effectiveness of the awareness raising activities of the project Refugee now - always human supported by the United Nations High Commissioner for Refugees (UNHCR) office in Skopje and conducted by the Center for Human Rights and Conflict Resolution in partnership with the Research, Education and Development (RED) Center, both from Skopje.
} 
their prejudices. The behavioral component was addressed through the follow-up activities that involved participants in humanitarian and/or advocacy actions that included their immediate surrounding.

\section{Measures and procedure}

The effects of the project activities on project participants were measured by using a questionnaire designed to assess participants' knowledge, attitudes and behavior regarding refugees. Two sets of measures of the participants' level of prejudice towards refugees were extracted from the original questionnaire and used in this study as indicators of: negative attitude towards refugees (12 items) and social distance (6 items). Both sets of measures contain items on Likert scale, asking participants to express their level of agreement (from fully agree to fully disagree) either on a five-point scale consisting of statements that reflect attitudes towards refugees or on a four-point Bogardus type social distance scale. Higher scores on both sets of measures indicate higher presence of prejudices among participants. The content of the items is presented in the Results section of this paper, together with the obtained data.

Both sets of measures were administered twice - once, before the participants' engagement in the project activities (at the very begging of the training workshop) to obtain the pretest measures and again, after their engagement in the project activities ended, to obtain the posttest measures. The time distance between pretest and posttest varied from one group of participants to the other, but most of them it was within an interval of 3 to 12 weeks. On both occasions, the questionnaire was administered in printed, pen and paper version, but in several cases, absent participants filled out the same questionnaire using an online platform.

\section{Participants}

The research was carried out on two groups (Group PRE and Group POST) and each of the two groups consisted of 124 participants that voluntarily enrolled in the awareness raising program. The structure of both groups with reference to the participants' sex and their participating status is presented in Table 1. The data in the table shows that almost half of the participants in both groups are high-school students (49.2\%), and among the rest of the participants there are university students (12.9\%) and unemployed youth (37.9\%). Majority of the participants (69.4\%) are females - males were minority in all participating categories.

All of the participants took part in the Awareness raising project that normally requires the same group of participants to be included in both conditions (in the pretest and posttest). Two reasons prevented that from happening. First, in the original sample, the number of participants in the pretest situation (a total of 149) was larger than the number of participants in the posttest situation (a total of 130) due to the difference in the number of those that participated in the training workshop and those that persuaded with the follow up activities and were also available to fill out the questionnaire after those activities ended. Second, it was impossible to simply exclude the missing participants in the posttest condition because the identification for a big 


\section{Security}

portion of them was not possible (due to the time interval between the two testing conditions, the self-assigned codes for identification did not overlap in many cases). Therefore, an additional strategy had to be employed to assure as much inter-group overlap between research participants as possible.

Table 1. Structure of the Group PRE/Group POST (in numbers and percentages)

\begin{tabular}{|l|rr|rr|rr|}
\hline & \multicolumn{2}{|c|}{ females } & \multicolumn{2}{c|}{ males } & \multicolumn{2}{c|}{ total } \\
\hline high-school students & 38 & $62.3 \%$ & 23 & $37.7 \%$ & 61 & $49.2 \%$ \\
\hline university students & 13 & $81.2 \%$ & 3 & $18.8 \%$ & 16 & $12.9 \%$ \\
\hline unemployed youth & 35 & $74.5 \%$ & 12 & $25.5 \%$ & 47 & $37.9 \%$ \\
\hline \multicolumn{1}{r|}{ total } & 86 & 69.4 & 38 & 30.6 & 124 & $100 \%$ \\
\hline
\end{tabular}

Thus, the selection of the research participants went through two phases. In the first phase, participants in the posttest condition with missing answers to the items of concern (either those that belong to the measures of prejudice, or those that indicate participant's sex or his/her participating status in the project) were excluded and the POST group ended up with 124 research participants that belong to the categories presented in Table 1 . In the second phase, the matching group of research participants for Group PRE was extracted from the initial group of participants in the pretest condition, based on two criteria: (a) the participants' sex and participating status; and (b) their opinion about refugees who enter the country expressed on a scale from 1 (very negative) to 5 (very positive). In order to prevent bias due to the difference in the initial opinion about refugees between Group PRE and Group POST, the comparative Group POST consisting of 124 research participants was established by excluding from each of the previously determined categories those that expressed the most negative opinion about refugees. After the selection was done, the Group PRE's opinion about refugees was close to neutral ( $M=3.17$, and $60 \%$ chose either positive or negative as their answer). The expectations are that most of the participants that belong to Group POST belong to Group PRE as well.

\section{Results}

Mean averages and accompanying standard deviations were calculated for each item in the two sets of measures of prejudices, as well as for all items that are included in each set. These means indicate the level of negative prejudices - higher means indicate higher presence of prejudices. Significance of difference between each pair of means obtained in the pretest and posttest condition is analyzed by using independent $\mathrm{t}$-test (for the reasons explained in the section Method: Participants). 
Table 2. Results on the participants' negative attitudes towards refugees in the PREtest and POSTtest situation

\begin{tabular}{|c|c|c|c|c|c|c|}
\hline \multirow{2}{*}{ items } & \multicolumn{2}{|c|}{ PRE } & \multicolumn{2}{|c|}{ POST } & \multirow{2}{*}{$t$} & \multirow{2}{*}{$p$} \\
\hline & Mean & SD & Mean & SD & & \\
\hline 1. & 1.75 & .92 & 1.16 & .45 & 6.43 & .000 \\
\hline 2. & 3.03 & 1.25 & 2.15 & 1.19 & 5.67 & .000 \\
\hline 3. & 2.06 & 1.08 & 1.40 & .83 & 5.44 & .000 \\
\hline 4. & 2.72 & 1.16 & 2.25 & 1.32 & 2.97 & .003 \\
\hline 5. & 2.12 & 1.14 & 1.34 & .74 & 6.38 & .000 \\
\hline 6. & 4.34 & .96 & 3.47 & 1.24 & 6.15 & .000 \\
\hline 7. & 3.26 & 1.17 & 2.48 & 1.18 & 5.20 & .000 \\
\hline 8. & 3.01 & 1.20 & 2.26 & 1.31 & 4.68 & .000 \\
\hline 9. & 2.43 & 1.37 & 1.89 & 1.25 & 3.20 & .000 \\
\hline 10. & 1.99 & 1.12 & 1.38 & .72 & 5.09 & .000 \\
\hline 11. & 2.15 & 1.18 & 1.73 & 1.06 & 2.91 & .000 \\
\hline 12. & 2.66 & 1.32 & 2.00 & 1.31 & 3.95 & .000 \\
\hline $\begin{array}{l}\text { Overall measure of } \\
\text { NEGATIVE ATTITUDES }\end{array}$ & 2.63 & .57 & 1.92 & .53 & 9.95 & .000 \\
\hline
\end{tabular}

Table 2 shows that results obtained for the set of 12 items assigned to measure negative attitudes on a Likert scale from 1 to 5 (1=most positive; $5=$ most negative). Figure 1 displays the content of the items and points to the four items (labeled with Asterix *) that are scored in reversed order - while in all other eight items, agreeing with the statement indicates negative attitude towards refugees (fully agree=most negative attitude), for these four items, disagreeing with the statement indicates negative attitude (fully disagree=most negative attitude).

The overview of the overall measures, as displayed in Table 2, signifies that, on the average, the participants entered the activities with neither negative nor positive attitudes towards refugees (the overall $M_{\text {pre }}=2.63$ is even less than 3, which is the meddle point on the 1-5 scale). However, the comparative mean for the posttest situation is significantly lower $\left(M_{\text {post }}=1.93\right)$, indicating decrease in the participants' negative attitudes that have transformed into rather positive ones. Results of the $t$-test performed on each item show decrease in the negative attitudes measured by each individual indicator in the set $(p<0,01)$. 
How much do you agree with the following statements:

1-Refugees have no other choice but to leave their country which is at war.*

2-Refugees of today are not in such a bad situation as refugees of the past.

3-Refugees are vulnerable and need special protection.*

4-International documents give more rights to the refugees than to the citizens of the country they come to.

5-We should all advocate for refugee rights.*

6-Dangerous people hide among the refugees.

7-Refugees bring various dangers for the countries through which they pass.

8-Refugees are a burden to the countries they come to because they increase expenses.

9-When I hear of the refugees' sufferings I wonder if anyone is concerned with my problems.

10-When I hear of the refugees' sufferings I want to do something to help them.*

11-The citizens should work on their own problems, rather than deal with helping refugees.

12-Refugees should be helped mainly by international organizations, not other countries and their citizens.

Overall measure of NEGATIVE ATTITUDES
1

2

3

4 5

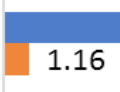

1.75
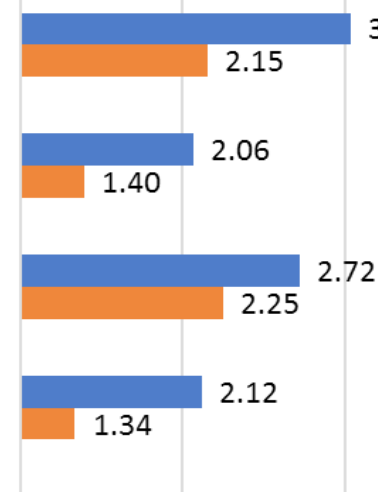

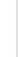

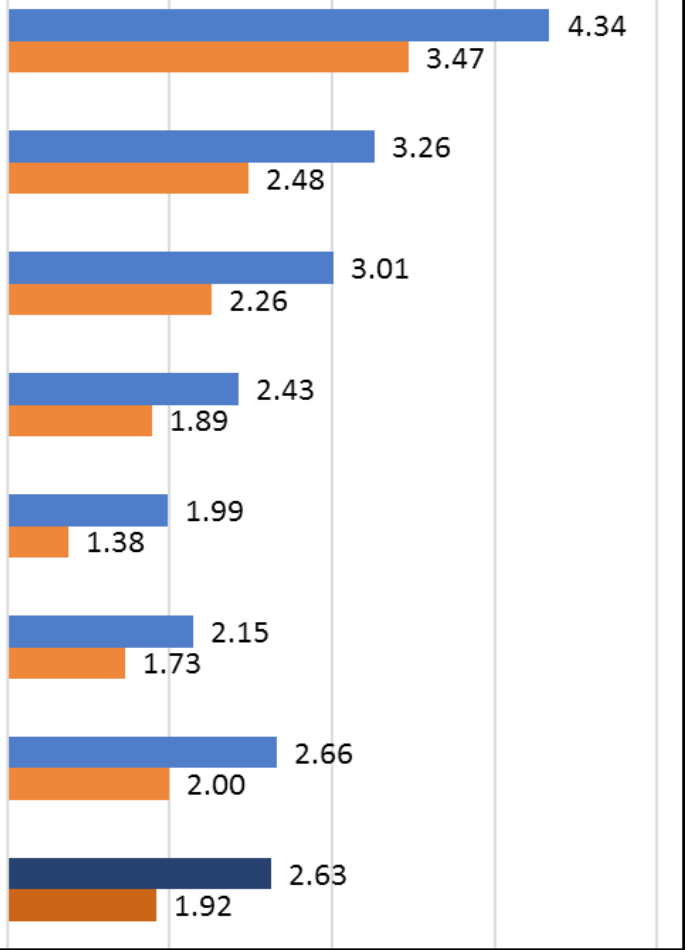

Figure 1. Comparative presentation of the means for the participants' negative attitudes towards refugees obtained in the PREtest and POSTtest situation (* denotes reversed items) 
Figure 1 presents, in a more illustrative manner, the mean differences for the individual items as well as for the overall set of items that compare the negative attitudes in the pretest and posttest situation. Having in mind that all visible differences in the means are statistically significant (Table 2), it is worth notifying that the item stating that Dangerous people hide among the refugees indicated the most negative attitude that was closest to the maximum point of 5 in the pretest situation $\left(M_{\text {pre }}=4.34\right)$ remained the most negative one as well as the only one that remains over the middle point of $3\left(M_{\text {post }}=3.47\right)$. The answers to all other items with pretest means above the medium point (Refugees bring various dangers for the countries through which they pass; Refugees of today are not in such a bad situation as refugees of the past; Refugees are a burden to the countries they come to because they increase expenses) have transformed (dropped for more than 0.75 scale points) indicating less negative attitudes (or attitudes that are closer to the positive end of the five-point scale). At the same time, even the most positive attitudes in the pretest situation (with $M<2.0$ ) that referred to Refugees have no other choice but to leave their country which is at war and When I hear of the refugees' sufferings I want to do something to help them were further improved in the posttest situation (for 0.59 / 0.61 scale points). According to the obtained results, the answers to items that refer to security issues (Dangerous people hide among the refugees and Refugees bring various dangers for the countries through which they pass) and economic issues (Refugees are a burden to the countries they come to because they increase expenses) have remained to reflect the highest concerns even though the comparison between the pretest and the posttest measures indicates the greatest decrease in the negative attitude.

Table 3. Results on the participants' social distance from refugees in the PREtest and POSTtest situation

\begin{tabular}{|c|cc|cc|c|c|}
\hline \multirow{2}{*}{ items } & \multicolumn{2}{|c|}{ PRE } & \multicolumn{2}{c|}{ POST } & \multirow{2}{*}{$t$} & \multirow{2}{*}{$p$} \\
\cline { 2 - 5 } & Mean & SD & Mean & SD & & \\
\hline 1. & 3.08 & .90 & 2.39 & .62 & 7.07 & .000 \\
\hline 2. & 3.12 & .94 & 2.48 & .68 & 6.13 & .000 \\
\hline 3. & 2.77 & .91 & 2.30 & .54 & 4.97 & .000 \\
\hline 4. & 2.83 & .82 & 2.28 & .56 & 6.14 & .000 \\
\hline 5. & 3.19 & .90 & 2.54 & .81 & 5.91 & .000 \\
\hline 6. & 3.78 & 1.07 & 3.25 & 1.02 & 4.01 & .000 \\
\hline $\begin{array}{l}\text { Overall measure of } \\
\text { SOCIAL DISTANCE }\end{array}$ & 3.13 & .74 & 2.54 & .56 & 7.01 & .000 \\
\hline
\end{tabular}

Table 3 contains that results attained for the set of six items that invite participants to state the degree to which they are accepting of refugees. Each item on this Bogardus-type social distance scale was scored to reflect the level of social distance, from 1 as a measure of 


\section{Secuurity}

no social distance to 4, measuring maximize social distance in the scale. The comparison of the overall measures obtained in the pretest and posttest situation implies that, on the average, the participants entered the activities with lower level of acceptance of refugees (the overall $\mathrm{M}_{\text {pre }}=3.13$ is much over 2.5 which is the meddle point on the 1-4 scale) but left with improved acceptance that is right in between distance and acceptance $\left(M_{\text {post }}=2.54\right)$. Results of the $t$-test applied on each item show decrease in displayed distance from the pretest to the posttest situation $(p<0,01)$, but the level of achieved acceptance vary from one item to the other.

Figure 2 presents the content of all items on the social distance scale and illustrates the mean differences for the individual items as well as for the overall set of items obtained in the pretest and posttest situation. Although the differences between the compared means for all items were found significant (Table 3), indicating improvement in the social acceptance of refugees, it is visible (though not unexpected) that the distance remains the highest when it comes to marrying a refugee and the lowest when it refers to accepting refugees to settle in the country and consequently, having a refugee as a friend or a colleague, while there is an obvious hesitation about acceptance of refugees as neighbors or teachers to one's own children.

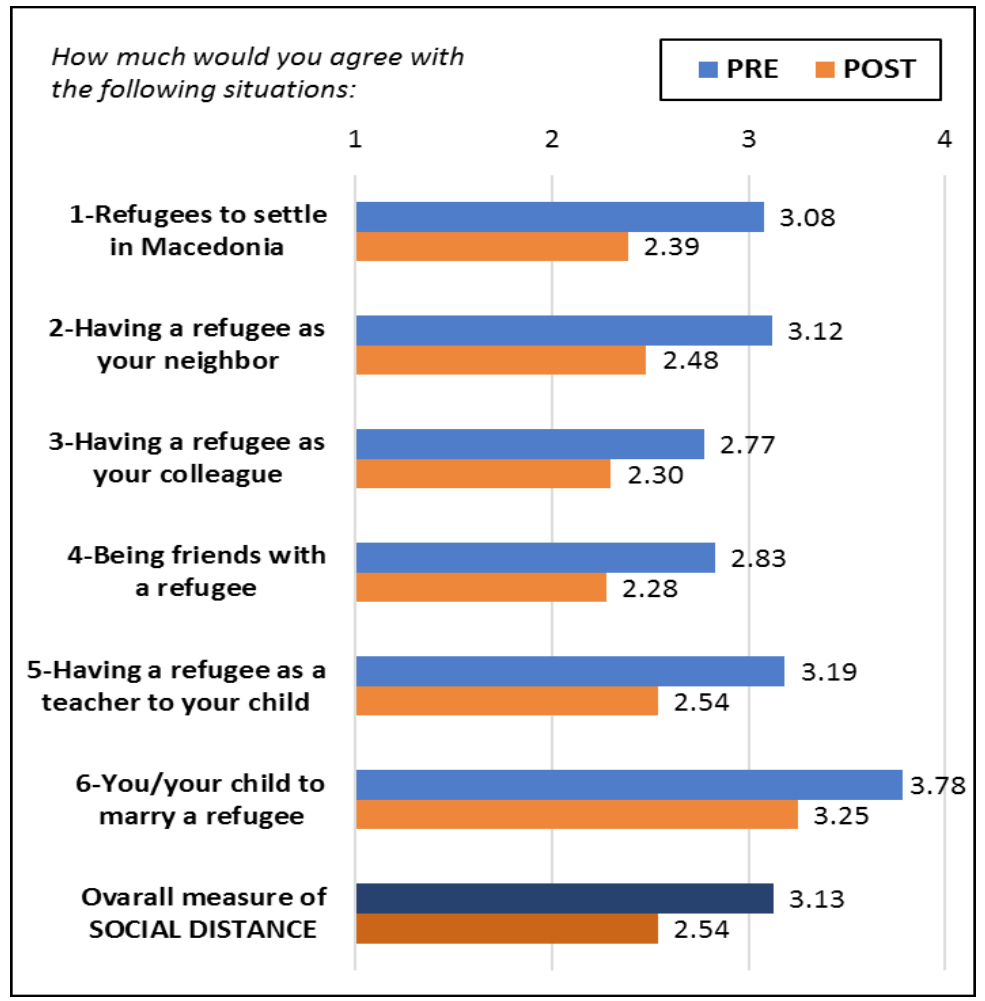

Figure 2. Comparative presentation of the means for the participants' social distance from refugees obtained in the PREtest and POSTtest situation 


\section{Conclusion}

Participants entered the awareness raising program with knowled ge that refugees are forced to leave their home country and with readiness to do something to help them. Furthermore, they held rather neutral attitudes towards refugees and felt socially distant from refugees. Regardless of that, both measures of prejudice against refugees appeared lower after implementation of the awareness raising activities than they had been before that. In other words, results from the statistical analysis have confirmed that participants in the awareness raising activities express higher social acceptance and more positive attitudes towards refugees after taking part in the awareness raising workshop and engaging in the follow-up activities.

The success of the overall awareness raising program can be ascribed to its design which incorporated recommendations that emerged from practical efforts employed for prejudice reduction in previous occasions. Since prejudice of all kinds is driven by ignorance (Griffith \& Chan-Kam, 2002), the actual activities faced participants with facts and figures which ensured that their opinion about refugees was no longer influenced by misinformation or exaggeration. The implemented awareness raising program was also in line with the evidence which has implied that emotive and value-driven arguments may be more powerful than facts and evidence in combating prejudices towards refugees. (Dempster \& Hargrave, 2017) and followed the reason that increasing awareness of the complexities of the situations in refugees' home countries and about refugees' sufferings could positively impact public sympathy (TENT, 2017). Going along with the argument that campaigns aimed at combating prejudices through modifying individuals' behavior must address common values (Crawley, 2009), the program confronted participants with violations of human rights as common values with broad societal consent. The awareness raising activities also responded to the findings that behavior change strategies are more effective when linked with on-the-ground community action that make the social environment more supportive of the desired results (Crawley, 2009).

Finally, the design of the awareness raising program took into account the recommendation that prejudice reduction activities will be more successful if based on a theory of change that defines objectives clearly and sends strong messages tailored to the targeted groups (Crawley, 2009). In fact, the program was developed to meet the outcomes of the following theory of change: If people are exposed to accurate information about refugees which address sufferings and violation of human rights and are engaged in social action that employ various means to transmit these information to their community, their prejudice towards refugees will be reduced. At the end, the intervention identified as awareness raising program managed to prove the assumptions brought by the initial theory of change.

The following participants' statements that illustrate their transformative experience regarding their preceding attitudes and feeling about refugees can serve as the best summary of the awareness raising program accomplishments:

- After the first few session of the workshop, during the break, we [students of psychology] discussed that it was not possible to expect change of the attitudes just because of the training, 
but by the end of the workshop we realized that we experienced actual changes and we actively started to fight our stereotypes. [Psychology student]

- It was very sad yesterday. Lot of us followed the sessions with tears in our eyes, because we realized where they [the refugees] came from and how incorrect our perceptions about them were, and that even we had hold such perceptions. [Comparative Literature student]

- When I came home from the training, I started asking my mother how she would like to see people in a foreign country act towards me if I were a refugee and separated from her. At the beginning, she refused to talk about refugees, but when she realized that I was insisting to get her answer, she said that I had apparently learned useful things during the training. [high-school student]

- Throughthisproject, Igotanew andclear picture about whotherefugees areand whyexactly they need help. Looking at the displayed photos, they incited in me a feeling of sadness, compassion and a kind of solidarity, and I wanted to transfer the same feelings and impressions to the rest of the citizens. [unemployed young person]

\section{References}

1. Allport, G.W. (1954) The Nature of Prejudice. Reading, MA: Addison-Wesley.

2. Augoustinos, M. \& Quinn, C. (2003) "Social Categorization and Attitudinal Evaluations: Illegal Immigrants, Refugees or Asylum Seekers?", New Review of Social Psychology, Vol.2, No.1, p.p.29-37

3. Breckler, S.J. (1984) "Empirical Validation of affects, behavior, and cognition as distinct components of attitude". Journal of Personality and Social Psychology, Vol.47, p.p.1191-1205

4. Bullard, S.M. (2015) Attitudes Toward Refugees Entering the United States of America. Honors Theses. 323. Honors College, The University of Southern Mississippi, http://aquila. usm.edu/honors_theses/323 (visited on March 10, 2018)

5. Crawley, H. (2005) Evidence on Attitudes to Asylum and Immigration: What We Know, Don't Know and Need to Know (Working Paper No. 23). University of Oxford, Centre on Migration, Policy and Society. http://www.compas.ox.ac.uk/media/WP-2005-023-Crawley_Attitudes_Asylum_ Immigration.pdf (visited on April 5, 2018)

6. Crawley, H. (2009) Understanding and Changing Public Attitudes: A Review of Existing Evidence from Public Information and Communication Campaigns. London: Diana, Princess of Wales Memorial Fund. https://www.barrowcadbury.org.uk/wp-content/uploads/2012/11/Understandingpublic-attitudes-a-review-of-existing-evidence-from-public-information-andcommunication-campaigns1.pdf (visited on April 5, 2018)

7. Dempster, H. \& Hargrave, K. (2017) Understanding public attitudes towards refugees and migrants. Working paper 512.London: Chatham House \& Overseas Development Institute. 
8. Esipova, N., Fleming, J. \& Ray, J. (2017) "New Index Shows Least-, Most- Accepting Countries for Migrants". Gallup, August 23, 2017 http://news.gallup.com/poll/216377/new-index-shows-least-accepting-countriesmigrants.aspx (visited on February 27, 2018)

9. Griffith, P. \& Chan-Kam, S. (2002) "Why Do We Hate Refugees? Public Opinion, Citizenship and Integration". In P. Griffith \& M. Leonard (Eds.) Reclaiming Britishness. (p.p. 91-101) London: The Foreign Policy Center

10. Hartley, L.K \& Pedersen, A. (2015) "Asylum Seekers and Resettled Refugees in Australia: Predicting Social Policy Attitude from Prejudice Versus Emotion", Journal of Social and Political Psychology, Vol.3, No.1, p.p. 142-160, D01:10.5964/jspp.v3i1.476

11. Hatton, T. (2016) "Immigration, public opinion and the recession in Europe". Economic Policy, Vol.31, No.86, p.p.205-246, D0I: 10.1093/epolic/eiw004

12. Karasapan, 0. (2017) "Refugees, Migrants, and the Politics of Fear". Brookings, April 12, 2017 https://www.brookings.edu/blog/future-development/2017/04/12/refugees-migrantsand-the-politics-of-fear/ (visited on March 5, 2018)

13. Murray, K. E. \& Marx, D.M. (2013) "Attitudes Toward Unauthorized Immigrants, Authorized Immigrants, and Refugees", Cultural Diversity and Ethnic Minority Psychology, Vol.19, No.3, p.p. 332-341, D0I: 10.1037/a0030812

14. Schweitzer, R., Perkoulidis, S.A., Krome, S.L. \& Ludlow, C.N. (2005) "Attitudes towards Refugees: The Dark Side of Prejudice in Australia". Australian Journal of Psychology, Vol.57, No.3, p.p. 170-179

15. TENT (2017) Public Perceptions of the Refugee Crisis (Year 2 Global Report) New York: TENT Foundation. https://www.tent.org/wp-content/uploads/2017/11/Tent_GlobalReport_ V6.pdf

16. UNHCR-The UN Refugee Agency (2018) "Figures at a Clance" http://www.unhcr.org/figures-at-a-glance.html (visited on April 8, 2018)

17. Verkuyten, M., Mepham K. \& Kros, M. (2017) “Public attitudes towards support for migrants: the importance of perceived voluntary and involuntary migration", Ethnic and Racial Studies, Vol.41, No.5, p.p. 901-918, D01:10.1080/01419870.2017.1367021

18. Wike, R. Stokes, B. \& Simmons, K. (2016) Europeans Fear Wave of Refugees Will Mean More Terrorism, Fewer Jobs: Sharp ideological divides across EU on views about minorities, diversity and national identity. Pew Research Center http://www.pewglobal.org/files/2016/07/Pew-Research-Center-EU-Refugees-andNational-Identity-Report-FINAL-July-11-2016.pdf (visited on March 10, 2018) 